\title{
FACULDADE DE MEDICINA DE RIBEIRÃO PRETO. A CRIAÇÃO DA PÓS-GRADUAÇÃO STRICTO SENSU: CURSO OU ÁREA ?
}

\author{
FMRP: THE FOUNDATION OF ITS GRADUATE STUDIES
}

Dalmo de S. Amorim

Docente Aposentado. Departamento de Clínica Médica. Faculdade de Medicina de Ribeirão Preto-USP.

Correspondência: Prof. Dr. Dalmo de Souza Amorim.

Rua Bernardino de Campos, 1236 - apto: 132 CEP: 14015-130. Ribeirão Preto - SP / Fone (Fax): (16)3636-4992,

e-mail: dalmosamorim@uol.com.br

Este texto parte da premissa de que estamos lidando com modelos. Entendido como a interpretação de uma realidade - modelo - não é algo que se copia: o modelo emerge do pensamento criativo com que se pretende representar uma realidade. A premissa arrasta a atribuição de função à interpretação de que deriva o modelo.

Essas considerações preliminares trazem atreladas observações. A primeira é a aceitação de que a interpretação de uma realidade - modelo - não implica em considerá-la como verdadeira. A segunda é uma indagação: e se a realidade mudar? Portanto, modelos são o que são, nada mais do que a natureza nos permite conceber em algum momento. Por último, outra indagação: deve-se interpretar ou também agir sobre a realidade, no sentido de mudá-la?

\section{O QUE ISSO TEM A VER COM O NOSSO ASSUNTO?}

Tem tudo a ver porque estamos lidando com um modo educacional - pós-graduação - que emerge da interpretação de uma realidade - modelo - à qual se atribui função. A aceitação de que estamos lidando com uma interpretação - modelo - no entanto, desde a origem, isto é, desde a fundação, trouxe um dilema no sentido da lógica formal: esse modo educacional deve ser desenvolvido como curso ou área, essa última também uma abstração. $\mathrm{O}$ dilema tem sua origem na trapalhada conceitual atropelada por aspectos normativos desde os primórdios do novo sistema educacional.
Para esclarecer o acima dito, vamos recorrer a exemplos de programas de pós-graduação alhures.

\section{PROGRAMA DE PÓS-GRADUAÇÃO EM PAÍSES EUROPEUS}

A esse respeito, recorro a meus escritos, de há trinta anos ${ }^{1}$. Naquela ocasião examinei programas de pós-graduação em dez países europeus, alguns deles na órbita do então socialismo soviético. A área médica, naquela publicação, tinha como fonte o livro editado por Woodford ${ }^{2}$. Para os propósitos desta apresentação selecionei alguns daqueles programas.

\section{Alemanha - República Federal}

Período médio de cinco anos em área de especialização. Durante o treinamento, a maior parte dos alunos desenvolvia atividade de pesquisa conducente à elaboração de tese (Dr. Med.). O título de especialista era requisito para a carreira acadêmica nas áreas de aplicação. Nas áreas básicas, o Doutorado era obtido mediante exame de tese.

\section{Alemanha - República Democrática}

Período médio de cinco anos de treinamento em especialidades. Cursos especiais eram organizados pelo Conselho Médico de Pós-Graduação: • Títulos Acadêmicos eram requisitos para a carreira universitária; • Dr. Med. mediante exame de tese; • o Doutorado, também exigindo tese, alguns anos após; - Dr. Med. era exigência importante para a ocupação de elevado cargo acadêmico. 


\section{Bulgária}

Treinamento profissional em três categorias: - treinamento individual, em "hospitais reconhecidos"; - cursos para grupos de médicos, organizados pela Academia de Medicina, com duração de vinte dias a seis meses; • palestras para médicos de um hospital, distrito ou região; Programas de Doutorado incluíam cursos e tese.

\section{Inglaterra}

Treinamento de duração variável em especialidades para obtenção de título, de acordo com as normas estabelecidas pelos Royal Colleges, o qual qualifica para o National Health System. Programas de Mestrado, em geral, para áreas tecnológicas. Programas de Doutorado com duração mínima de 33 meses. Os programas de pós-graduação eram supervisionados pela British Postgraduate Medical Federation.

E se a realidade mudar? O modelo não será o mesmo porque a interpretação corresponde a novas realidades. E estas surgiram: - regimes políticos se alteraram, caso dos países do Leste Europeu; • países abriram mão de sua autonomia relativa (não a soberania) para integrar-se em "blocos de nações", caso da União Européia; • novas abordagens nos métodos de ensino e aprendizagem.

Woodford ${ }^{2}$ apontou que o simpósio então realizado tinha como função o exame (interlocking) de sistemas de assistência à saúde, e educação e pesquisa médicas em cada país. A discussão entre os sistemas nacionais poderia possibilitar a aplicação de solução de problemas semelhantes de um país para outro. Há, desde então, nova geografia política, de que a Declaração de Bolonha é exemplo: a completa revisão do sistema de ensino superior europeu. Ainda em seus primórdios, a Declaração tem como elemento mais visível a graduação, em ciclos, que conduzem à qualificação para o mercado naquele continente. É antecipável que logo virá alcançar os modos de estudos após a graduação, com um novo interlocking de sistemas.

\section{MODELO DE PÓS-GRADUAÇÃO: A NORTE-AMERICANA}

Embora a doutrina de pós-graduação nos Estados Unidos se afigure precisa e os estudos culminem com a concessão de títulos acadêmicos hierarquizados, não existe uniformidade entre as diversas universida- des, o que em parte se explica pelo grau de autonomia acadêmica e pela descentralização do ensino.

A formação especial para a pesquisa e a atividade criativa é garantida por uma etapa de formação acadêmica "pura" que resulta na obtenção de um Mestrado (M.Sc.) ou Doutorado (Ph.D.) como requisito da carreira universitária e de investigação. Mas, em geral, o Mestrado e o Doutorado profissionais têm, naquele país, cunho de predominância técnica ao invés de acadêmica.

A pós-graduação - o nome e o sistema - tem sua origem próxima na própria estrutura da universidade norte-americana, compreendendo o college como base comum de estudos e as diferentes escolas graduadas que geralmente requerem o título de bacharel como requisito de admissão.

Em virtude dessa organização, a universidade acha-se dividida em dois grandes planos que se superpõem hierarquicamente: undergraduate e graduate. Na primeira encontram-se os cursos ministrados no college conducentes ao B.A. e ao B.Sc. A segunda abrange os cursos de pós-graduados, principalmente aqueles que correspondem a estudos avançados, visando aos graus de Mestre e Doutor.

Esses modos educacionais se caracterizam pela grande flexibilidade atribuindo-se aos candidatos larga margem de liberdade na seleção de matérias (isto é, renegando as práticas dos cursos), sendo os alunos assistidos e orientados por um diretor de estudos, em regime tutorial. São usados de preferência modos de ensino tais como seminários, programas de pesquisa, trabalhos de laboratório etc. que visam estimular a iniciativa criativa do aluno. O que se tem em vista é menos fazer o candidato absorver passivamente conhecimentos já sabidos e, sim, desenvolver sua capacidade de criação e juízo crítico, levando-o a exercer, por si mesmo ou em colaboração com orientador, a atividade de pesquisa.

$\mathrm{O}$ aspecto da realidade a considerar no modelo norte-americano é o de que, nas áreas de aplicação, a demanda de profissionais especializados se faz sentir agudamente no mercado de trabalho. Disso decorre que o relacionamento entre a pós-graduação acadêmica e as áreas profissionais é diferente, pois essas últimas não podem prescindir de uma base de aplicação técnica.

Em muitos Estados, naquele país, o título de Mestre é de utilidade como sinal de competência profissional, por exemplo, na Administração, Arquitetura ou Engenharia, sendo o título garantia de melhor re- 
muneração. No ensino superior, em certas carreiras, no entanto, é de menor valor. Em um número restrito de universidades, programas de pós-graduação são oferecidos em áreas clínicas, ainda que mais freqüentes nas áreas básicas. Existem universidades, como a de Princeton, como exemplo, que praticamente apenas oferecem programas de Doutorado.

E se a realidade mudar?

Nos Estados Unidos, ao longo do tempo, detectam-se mudanças mercê do desenvolvimento científico e tecnológico e dos métodos de ensino e aprendizagem. Coleção de ensaios revela os objetivos - a função - de novas escolas médicas: uma grande variedade de abordagens, incluindo desde a ministração de disciplinas isoladas até os objetivos e a relação das escolas médicas com a universidade ${ }^{3}$.

Na graduação, programas combinados M.D. e $\mathrm{Ph}$.D. são oferecidos, embora ainda em número limitado. Programas de Doutorado tornam-se mais e mais interdisciplinares, tais como Biomedical Imaging, Immunology, Molecular Neurosciences, Tumor Biology etc. Também devem ser referidos os Master's Programs in Health - Related Sciences, de que Physical Therapy serve como exemplo.

\section{PÓS-GRADUAÇÃO ADOTADA NO BRASIL}

\section{Diretrizes legais e normas}

A primeira Lei de Diretrizes e Bases da Educação Nacional - Lei no 4 024, de 20 de dezembro de 1961 - ao considerar os diferentes tipos de curso superior dá destaque à pós-graduação ${ }^{4}$. De fato, a letra b do artigo 69 daquela lei serve de balizamento para a organização dos cursos subseqüentes à graduação. A exegese do artigo poderá discernir elementos básicos que nos permitem interpretar o conceito à vista da indefinição do texto legal.

b- de pós-graduação, abertos à matrícula de candidatos que hajam concluído o curso de graduação e obtido o respectivo diploma.

Admitida a doutrina de pós-graduação, cujo aceno foi apenas delineado na letra e artigo acima referidos, daquela lei, o modelo - mestrado e doutorado - emerge do Parecer no 977/65, da lavra de Newton Sucupira, prolatado no extinto Conselho Federal de Educação. O Parecer daquele Conselheiro dá ao tópico a clareza, a consistência e a condição para o seu desenvolvimento ${ }^{5}$.
Se a função fundamental da pós-graduação é a educação complementar à graduação, os modelos então delineados ou ativos bastariam sem que tornasse necessário definir pós-graduação e particularizar os seus princípios e objetivos diferenciados, a exemplo da situação existente no país - fonte de inspiração desse modo de estudos.

Mas cada país necessita examinar as suas próprias necessidades a fim de estabelecer as bases para os seus programas educacionais. A esse respeito, a principal característica da ação do poder público nacional foi a de definir uma política operacional de acordo com as condições educacionais e sociopolíticas. Entende-se que o legislador desconfiado da expressão pós-graduação, percebendo-lhe a dificuldade de manipulação e seu poder antes sugestivo que de instrumento de precisão designativo, atribuiu-lhe objetivos específicos.

Entendeu o legislador que os estudos realizados após a graduação deveriam ser classificados em dois grandes grupos, criando modelos de acordo com a interpretação da realidade nacional. O primeiro - o da pós-graduação stricto sensu - conducente aos graus acadêmicos de Mestre e Doutor. O outro - o da pós-graduação lato sensu - compreendendo aperfeiçoamento, especialização, extensão e outros.

A particularização definia, entre nós, as diferenças de objetivos - isto é, a função - dos dois novos modos de práticas educacionais. A pós-graduação stricto sensu visa criar uma elite científico-cultural criativa de professores e pesquisadores de alto nível, prevendo a sua participação na solução de novos problemas relevantes. A pós-graduação lato sensu visa o preparo e o aperfeiçoamento para o exercício profissional, qualificando-o, a saber, para a geração do capital humano necessário para o funcionamento tecnológico. Era a teoria que dá função técnica a Educação. O depoimento de Anísio Teixeira ${ }^{6}$, no crepúsculo dos anos sessenta, na Câmara de Estudos para a Reestruturação do Ensino Superior, é expressivo quanto aos debates travados nas duas décadas anteriores.

Mas só houve desenvolvimento do sistema de pós-graduação stricto sensu - definido no Parecer no 977 , de dezembro de 1965, após a reforma universitária de 1968. A Lei no 5 540/68 fixa as normas de organização e funcionamento do ensino superior ${ }^{7}$. Até então, aqui e acolá, eram oferecidos programas de especialização ou de doutorado ao estilo europeu, em cursos que permitiam ou até mesmo exigiam a sua implantação, como aqueles da saúde. 


\section{MODELO: UMA INTERPRETAÇÃO DE UMA REALIDADE}

\section{Uma interpretação: a do filósofo}

O Conselheiro Newton Sucupira ${ }^{5}$, relator do Parecer no 977/65, usa exemplo de sua própria vivência para discorrer sobre os requisitos necessários aos títulos acadêmicos, Master e Ph.D., na universidade norte-americana, por ele cursada. Para o Doutorado, dentre outras exigências, incluia-se um grande exame (comprehensive examination), compreendendo: • a especialidade de opção, a história da Filosofia, matérias do domínio conexo e, $\bullet$ o exame final sobre o assunto de que trata a tese. Para o Mestrado, além de outras exigências, era obrigatória a apresentação de ensaio "organizando e interpretando dados relativos a um problema geral", preparo que constitui "contribuição aos conhecimentos novos sobre um tema aprovado".

\section{Uma interpretação: a do médico}

Para disciplinar a pós-graduação stricto sensu na área médica, foi publicado o Parecer no 576/70, prolatado pelo $\mathrm{Cons}^{\circ}{ }^{\mathrm{R}}$ ubens $\mathrm{Maciel}^{8}$. O relator destaca a peculiaridade no ensino médico: o homem é o seu objeto e o seu instrumento. Em seu parecer, aquele conselheiro dá ênfase à residência médica, ou seja, à prestação de serviços, em tempo integral, em hospital credenciado para o ensino, em razão de seus recursos materiais e de qualificação do corpo médico. No entendimento daquele ilustre relator não havia antagonismo, antes superpossibilidade, entre a residência e os cursos de mestrado e doutorado.

O Cons ${ }^{\circ}$ Rubens Maciel, em seu parecer, expande suas considerações, das quais relevo:

- destaque entre o ciclo básico e o ciclo profissional tende a acentuar-se, emergindo junto ao médico, com pleno reconhecimento legal, o Bacharel em Ciências Biológicas, modalidade médica, com a mesma formação básica, mas esquivando-se de perlustrar o ciclo clínico, em favor do encurtamento do tempo de sua formação e de uma melhor capacitação ao ensino, à pesquisa, e à aplicação das ciências biomédicas;

- não seria necessário ou justo fazer anteceder a residência ao curso. É possível compatibilizar a realização simultânea de residência e créditos, com a residência e pesquisa. Por outro lado, seria injusto alongar uma formação que, no caso de outras profissões, completa-se em tempo mais curto.
A exposição culmina com a divulgação de Normas Complementares, das quais pinço três artigos.

Art. 2o Poderão inscrever-se nos cursos de pós-graduação em Ciências Biológicas, modalidade médica, os bacharéis da área de graduação correspondente, e os portadores de diploma de médico ou de curso superior da área da saúde que tenham cursado, com aproveitamento, as matérias básicas do currículo mínimo do curso de graduação em Medicina.

Art.3o Os cursos de pós-graduação em Medicina serão ministrados a médicos, em regime de Residência e dedicação exclusiva.

Art. $4^{\circ} \mathrm{O}$ processo de credenciamento de curso de graduação em Medicina abrangerá o exame meticuloso das condições do Hospital onde terá lugar a Residência.

A matéria viria a ser posteriormente regulamentada. A Resolução no $11 / 77^{9}$ do Conselho Federal de Educação fixa normas para o credenciamento de curso de pós-graduação em Medicina e cria, entre outras, a exigência de Certificado de Residência Médica na área de concentração, com a duração mínima de dois anos. O Decreto no 80231 legisla sobre a Residência Médica ${ }^{10}$.

\section{NORMAS ADOTADAS NA UNIVERSIDADE DE SÃO PAULO}

Em um país com pouca descentralização das decisões emanadas do governo federal - a burocratização do Estado - as normas de pós-graduação adotadas na USP seguem aquelas acima apontadas. As duas Portarias - GR no 885 e GR no 1212 - serão apresentadas adiante escoimadas de muitos aspectos formais.

GR no $885^{11}$, de 25 de agosto de 1969 , tendo em vista deliberação do Conselho Universitário em sessões de 14 de abril e 11 de agosto do mesmo ano, segue o campo doutrinário que deflui do Parecer no 977/65. A portaria dispõe sobre o regime de pós-graduação

- Os programas de pós-graduação compreenderão cursos avançados, na área de concentração escolhida pelo candidato, bem como em áreas complementares. Por área entende-se o campo específico em que o candidato deverá desenvolver as suas atividades de pesquisa, ou equivalente, e por área complementar outras matérias consideradas necessárias ou convenientes para complementar a sua formação. 
- O candidato (ao mestrado ou doutorado) escolherá o seu orientador de uma lista de docentes, cabendo ao orientador fixar o programa de estudos de cada um dos candidatos. O currículo organizado para o aluno poderá envolver vários Departamentos, institutos ou mesmo áreas mais amplas, inclusive instituições não ligadas à USP.

- Além das provas de avaliação de aproveitamento, estabelecidas para cada curso ou atividade, o candidato (ao mestrado ou doutorado), para fazer jus aos correspondentes graus, deverá submeter-se a exames gerais de qualificação, de acordo com critérios estabelecidos pela Comissão de Pós-Graduação da Instituição. Os exames gerais de qualificação deverão cobrir as matérias de concentração e complementares e serão realizados no Departamento onde se situa a área de concentração escolhida pelo candidato.

- O doutorado nos setores básicos terá uma das seguintes designações: Artes, Ciências Humanas, Filosofia e Letras. Como subtítulo, será indicado, no diploma, a área de concentração escolhida pelo candidato. Nos setores profissionais, o doutorado será designado de acordo com os cursos de graduação correspondentes. O mestrado será qualificado pelo curso de graduação, área ou matéria a que se referir.

GR no $1212^{12}$, de 25 de junho de 1970 , de acordo com o pronunciamento da Comissão Central de Pós-Graduação da USP, cuida dos Cursos de PósGraduação da $F M R P$. O Regulamento atende às exigências daquela Portaria GR no 885 , além de sujeitálo às normas que vierem a ser estabelecidas.

\section{PÓS-GRADUAÇÃO NA ÁREA MÉDICA}

A implantação da pós-graduação stricto sensu trouxe para a universidade brasileira uma série de controvérsias, particularmente na área médica. Dessa forma, ela foi regulamentada pelo Parecer no 576/ $70^{8}$ que, ao considerar as suas particularidades, procurou compatibilizar a pós-graduação acadêmica com a profissionalizante. Entre outras exigências foi incluída a obrigatoriedade dos cursos em regime de Residência e dedicação exclusiva.

Daí que a Comissão Central de Pós-Graduação da USP baixou normas ${ }^{13}$, como condição para autorizar o funcionamento dos cursos de pós-graduação na área médica, a fim de que esses pudessem ser credenciados pelo Conselho Federal de Educação. Esses programas (tanto para mestrado como para doutorado), além de outras exigências, deveriam prever o cumprimento obrigatório da Residência em regime de dedicação exclusiva, com duração mínima de dez meses, não podendo o tempo ser inferior a 1200 horas.

Essa resolução não foi inconseqüente para nós, que havíamos conduzido a discussão para a implantação da pós-graduação stricto sensu, admitindo diferenças de objetivos dos sistemas discutidos. A distinção está em que a especialização etc. qualifica a natureza específica de um curso, enquanto a pós-graduação stricto sensu é de natureza acadêmica, de aprimoramento didático-pedagógico e de pesquisa mesmo nas áreas profissionais.

\section{PÓS-GRADUAÇÃO STRICTO SENSU: CURSO OU ÁREA?}

Pode a pós-graduação stricto sensu ser oferecida sob a forma de curso? A resposta, provavelmente, é não. Curso é entendido como uma série de disciplinas (ou matérias), algumas praticamente obrigatórias (por normas de legislação) e, outras, opcionais (arbítrio de cada escola, por "tradição" etc.), organizadas dentro de uma certa lógica, ministradas de forma isolada, distribuídas por série, em matrizes curriculares comuns a todos os alunos, em determinado período de tempo (semestres ou anos letivos).

Os cursos, em geral, funcionam como processo uniforme, supostamente homogêneo, apesar de as diretrizes educacionais nacionais conferirem liberdade de iniciativas pedagógicas na organização do ensino superior, o que revela certa tipologia dos responsáveis pelo ensino.

O aluno, sem quase nenhuma opção, deve seguir o curso em seu conjunto. Essa situação ocorre ao lado de inadequado sistema de avaliação e promoção: elas ocorrem "em bloco", dos alunos de mesmas turmas. Não há acompanhamento "de perto", que identifique outros atributos além do desempenho (notas ou conceitos) em provas ou testes de outra natureza. A criatividade, as atitudes e o interesse do aluno, particularizado, não são atributos avaliados, por insuficiência do docente, da sobrecarga das suas atribuições e razões de outra natureza. Dentre essas últimas, há até mesmo o histórico cultural do aluno que a elas não foi submetido e que a elas torna-se resistente e a elas não adere. Em geral, a organização departamental (com 
seus regulamentos, fracionamentos, estilos cognitivos etc.) é a unidade, plena, encarregada da ministração (de sua cota), no curso. Ele, o departamento, é ente isolado com a tarefa de transmitir o saber já sabido.

A premissa básica do novo sistema educacional - pós-graduação stricto sensu - é aquela que não estamos lidando com "coleção de conhecimentos" (disciplinas) representativos de categorias profissionais (especialidades). A essência da pós-graduação stricto sensu é a área ${ }^{14}$ : em sua virtualidade, ela rejeita o entendimento de que os estudos se limitem a um "ambiente fechado". A área é o campo de conhecimento que constituirá o objeto dos estudos do candidato (ao mestrado ou doutorado); e, por domínio conexo, qualquer matéria não pertencente àquele campo, mas considerada necessária para complementar sua formação. O sistema preconizado é multidepartamental e interdisciplinar.

É indisputável que estamos lidando com sistema educacional tutorial. O candidato, repita-se, rezam as normas, escolherá o seu orientador, cabendo a este último fixar o programa de estudos de cada aluno, de modo singularizado. A avaliação do aproveitamento, também singularizado, é (ou deve ser) feita através de exames, trabalhos e projetos, bem como pelas atitudes, criatividade, interesse e participação daquele aluno, especial, privilegiado, sob orientação definida quando do seu ingresso no programa. O mérito do sistema vai além (e não se limita) do preparo de uma tese de doutorado ou dissertação de mestrado.

\section{FACULDADE DE MEDICINA DE RIBEIRÃO PRETO}

\section{O que tem a ver com o nosso assunto?}

Tem tudo a ver. As considerações até aqui feitas têm o propósito de apresentar, de modo sucinto, condições existentes por ocasião da fundação da pósgraduação em nossa escola. Este texto, breve, se limita a registrar alguns pontos da memória histórica ${ }^{15}$. Ele não pretende ser muito explicativo do que ocorria no cenário nacional e nem no ambiente interno da instituição, naquela época.

Seguir um bom modelo não é o mesmo que copiá-lo. Newton Sucupira, em 1965, oferece a pósgraduação norte-americana como exemplo. Ele não propôs, como se supõe amplamente, uma visão literária. Temos de reconhecer que ele usou a palavra como adjudicatória de conceitos: eles não são somente uma proposição de modos de ensino. Mais do que isso: era, de fato, uma campanha clara e deliberada contra arcaísmos. Aquele Conselheiro adverte sobre os condicionamentos - condições apropriadas e desejadas para o funcionamento - os quais devem ser zelados - sob o risco de repetirmos, na maioria dos casos, os modos da graduação.

Tínhamos, nessa escola, esses condicionamentos?

Sim, tínhamos. Para ilustrar, até o ano de 1979, quando expira o direito daqueles nossos docentes já inscritos no sistema antigo, estilo europeu, foram defendidas 149 teses de doutorado: 62 em departamentos básicos e 87 em departamentos clínicos. Essa experiência, decorrente da existência de condições favoráveis, permitiu a imediata implantação de treze programas - mestrado e doutorado - em seis áreas básicas e sete áreas clínicas. Não pode passar despercebido que algumas, por exemplo, a Clínica Médica, reconheceu a ausência de tradição do Mestrado em nossas escolas médicas. Entretanto, aquela área considerou a possibilidade do Mestrado por entender que assim poderia atender as circunstâncias de situações individuais, algumas só inteiramente discerníveis no transcorrer do programa de estudo.

Não se deve omitir que, no início dos trabalhos, fomos atropelados por uma trapalhada de conceitos e atos normativos. Para atendimento de preceitos legais, as normas e regulamentos então prevalentes estão contidos em nosso primeiro documento de divulgação dos $\operatorname{cursos}^{16}$.

Sim, é verdade que tínhamos as vantagens da pré-existência de condições, como acima assinalado, no que tange às atividades de pesquisa conducentes ao doutorado, embora, em muitas situações, setoriais. Mas devemos referir melhor o que seriam as limitações e as qualidades relativas à nova situação em espécie.

\section{Da Comissão de Pós-Graduação}

Ela era integrada por pessoas de reconhecida experiência em pesquisa, com destaque para Maurício Rocha e Silva. Nenhum dos integrantes dessa comissão, contudo, tinha vivência no sistema educacional sendo implantado. O que possuíamos, além das vivências pessoais em investigação científica, era um elenco de normas e regulamentos que deveriam ser interpretados - portanto, um modelo - à vista da experiência anterior da instituição. Essas condições básicas, fundamentais, nem sempre estavam disponíveis 
alhures, o que explica a diferença de interpretação como modelo - e as resistências e hostilidades por nós enfrentadas em nível mais amplo da discussão da pós-graduação ${ }^{17}$.

\section{Departamentalização dos programas}

O modo preconizado na pós-graduação stricto sensu é, em essência, interdepartamental e (sobretudo) interdisciplinar. A transposição de Departamento (com suas múltiplas disciplinas não-integradas e estilos cognitivos próprios) em Área, um ente abstrato, era mais do que um exercício semântico. Não era tarefa fácil compreender, aceitar e funcionar em um modo de organização e oferecimento de conteúdos curriculares distintos do até então. Teria sido mais fácil, apregoava-se, apresentá-los em disciplinas (representativas de especialidades) do que em "unidades temáticas" que o modo educacional reclamava.

\section{Do domínio conexo}

Nenhum candidato - mestrado ou doutorado poderia completar a sua formação acadêmica juntando o número de créditos exigidos dentro de uma única área. A premissa era a que deveriam ser obtidos créditos outros, em domínio conexo, de modo a permitir a composição coerente de programas de estudos, singularizados, para cada aluno.

Entretanto, como o oferecimento das disciplinas complementares dependia da boa vontade e disposição dos docentes por elas responsáveis (e nem sempre isso ocorria), resultaram sérias distorções na organização dos programas individuais. Esses desvios mereceram reparos críticos. No simpósio nacional, aqui realizado, no dizer de Maurício Rocha e Silva ${ }^{17}$ "o recurso é usar o arco e a flecha no que aparecer pela frente e atirar no que estiver mexendo, como bom caçador".

\section{Dos Exames gerais de qualificação}

Ao adotarmos o modelo norte-americano, importamos também o modo de verificação da integração dos conhecimentos e suas coerências com o objeto da dissertação ou tese. Esse exame é tido como comprehensive, conforme interpretação assinalada por Newton Sucupira.

Dado o histórico disciplinar da graduação, o que inclui a performance de cada professor, e apesar da criação de uma "unidade temática", os Exames Gerais de Qualificação não tinham a devida abrangência doutrinária, interdisciplinar. Havia repetição de avali- ação já feita, no âmbito de disciplina isolada, quando do trânsito do aluno por ela. A redundância causou, na época, acerbadas reclamações dos alunos.

\section{Do pessoal docente}

Tínhamos, sim, pessoal titulado e habilitado para dos programas participar. Mas a situação do professor, de posse do título, mudou: ele deveria assumir função tutorial. Sob os aspectos - conceitual e normativo - a marca maior é a de um professor-guia dos estudos individuais. Cabe ao orientador fixar o programa de estudos do aluno, bem como pela sua avaliação cognitiva, atitudinal etc.

Havia ainda mais. Ainda que a escolha do orientador seja sob o aspecto regulamentar iniciativa do aluno, não devia ser permitido que o orientador aceitasse tal número de orientados de que resultasse prejuízo na sua função específica, em detrimento do aluno.

\section{Condição de infra-estrutura}

Acreditávamos ter os recursos necessários para o desenvolvimento das novas atribuições. Na verdade tínhamos, sim, os meios para atender às exigências correntes (as atividades de ensino e pesquisa do pessoal docente), que eram muitas. Mas não as tínhamos para atender um sistema de demanda crescente.

Foram necessários alguns anos até o reconhecimento de nossos programas de pós-graduação stricto sensu pelo Conselho Federal de Educação. O que os tornava inaptos a postular apoio financeiro por órgãos estatais. Obviada essa exigência formal, candidatamo-nos. Por exemplo, a Área de Concentração Clínica Médica, na personalidade administrativa de Departamento pleiteou (e obteve) recursos orçamentários extraordinários, junto à Financiadora de Estudos e Projetos (Finep). Esses recursos foram concentrados, prioritariamente, na modernização do Laboratório Experimental. Sob a manta do modo interdisciplinar próprio do sistema de pós-graduação stricto sensu, comprometeu-se a área com programa que visava a formação de recursos humanos - professores e pesquisadores - no âmbito do conceito, em área.

A mudança da interpretação da realidade, contudo, por parte daquela financiadora, não foi inconseqüente para alguns de nós. As renovações contratuais, posteriores, além de lentas e descontínuas, viriam alterar a característica básica do programa e direcionar o apoio, por aquele órgão governamental, para alguns projetos por ele considerados prioritários. Importan- 
tes, sim, que poderiam ou deveriam ser apoiados em qualquer situação, mas por sua seletividade, não mais configuravam o nosso entendimento.

\section{Plano Diretor}

Cerca de duas décadas mais tarde, ao início dos anos 90, a Faculdade de Medicina de Ribeirão Preto decidiu reexaminar-se em cuidadoso e detalhado processo designado Avaliação da Conjuntura \& Planejamento Prospectivo. Ele culminou na elaboração de Plano Diretor ${ }^{18}$.

No desenrolar do processo - de auto-avaliação, secundada por avaliação externa - no que pertine à pós-graduação - mestrado e doutorado - foram destacados:

- todas as áreas tinham forte vínculo com a estrutura departamental que lhes deu origem, o que, em parte, explica que treze delas puderam ser implantadas tão pronto o sistema foi regulamentado. Se a velocidade de expansão tornou-se possível, graças ao forte vínculo departamental, não há como deixar de reconhecer que essa subordinação tornou-se um óbice à criação de novas áreas de objetivo interdisciplinar e interdepartamental;

- apontou áreas emergentes, prioritárias, tidas como estratégicas, cuidando de torná-las multidepartamentais e interdisciplinares;

- o mestrado deveria ser exceção à norma institucional;

- oferecimento, prioritário, de programas de doutorado e de pós-doutorado, cuidando de afastar qualquer idéia de curso no pós-doutorado;

- no que dizia respeito ao ambiente geográfico, a zona de influência deveria ser mais extensa, transcendendo as fronteiras regionais. Havia nítido conflito com a missão da instituição, no fato de ter ela se revelado, na pós-graduação, como centro imigrador.

- não será demais mencionar a possível combinação de programas M.D. e Ph.D. Durante o curso de graduação o aluno poderá, em qualquer etapa, optar pelo Bacharelado em Medicina ou em Biomedicina, ou em ambas as modalidades ou, eventualmente, completar programas de pós-graduação após o Bacharelado em Biomedicina sem prejuízo de posterior graduação em Medicina.

\section{REFERÊNCIAS}

1 - Amorim DS.Pós-Graduação área de aplicação: clínica médica. Medicina (Ribeirão Preto) 1976/1977; (9/10): 93-106.

2 - Woodford FP, editor. Medical research systems in Europe. A Ciba Foundation Symposium. Amsterdam: Associated Scientific Publishers; 1973.

3 - Popper H, editor. Trends in new medical schools. New York: Grune \& Stratton; 1967.

4 - Souza PNP. LDB e educação superior: estrutura e funcionamento. 2a ed. São Paulo: Pioneira; 2001.

5 - Brasil. Conselho Federal de Educação. Parecer no 977/65. Definição dos cursos de pós-graduação. Documenta 1965 dez; 44:67-77).

6 - Teixeira A. Uma perspectiva da educação superior no Brasil. R Bras Estud Pedagog ( Rio de Janeiro) 1968; 50 (111): 21-82.

7 - Brasil. Lei $n^{\circ} 5$ 540. Diario Oficial da União, Brasilia 1968 dez.03.

8 - Brasil. Conselho Federal de Educação. Parecer nº 576/70. Pós-Graduação em Medicina. Documenta 1970 ago; 117: 225-36.

9 - Brasil. Conselho Federal de Educação. Resolução n 11/77. Normas para o credenciamento de curso de pós-graduação em Medicina. Documenta 1977 jun; 199: 398.

10 - Brasil. Presidência da República. Decreto nº 80 231. Diário Oficial da União, Brasília 1977 set. 06; Sec. I - Parte I.

11 - Universidade de São Paulo. Portaria GR. no 885, de 25 de agosto de 1969. Dispõe sobre o regime de pós-graduação na Universidade de São Paulo.

12 - Universidade de São Paulo. Portaria no 1212, de 25 de junho de 1970. Aprova o Regulamento dos Cursos de Pós-Graduação da Faculdade de Medicina de Ribeirão Preto da Universidade de São Paulo. Diario Oficial do Estado de São Paulo, São Paulo 1970 jun. 30.

13 - Universidade de São Paulo. Norma nํ⒌ Pós-Graduação na Área Médica. Diario Oficial do Estado de São Paulo, São Paulo 1970 dez.18; 56.

14 - Amorim DS. Área: Conceito e Práxis. Medicina (Ribeirão Preto) 2006;39 (2): 265-8.

15 - Amorim DS. Memória histórica da Pós-Graduação. Medicina (Ribeirão Preto) 2005;38:(2)164-7.

16 - Universidade de São Paulo. Faculdade de Medicina de Ribeirão Preto - Cursos de pós-graduação nas áreas básicas e clínicas. Mestrado e Doutorado. Boletim 1971-1972.

17 - Rocha e Silva M. Pós-Graduação nas Áreas biomédicas. In: III Simpósio Nacional de Pós-Graduação nas Áreas Biomédicas. Faculdade de Medicina de Ribeirão Preto. Ribeirão Preto; 1975.

18 - Universidade de São Paulo. Faculdade de Medicina de Ribeirão Preto. Plano Diretor, aprovado pela Congregação, em sua 564를 Sessão Extraordinária, de 6 de dezembro de 1991. 